\title{
Short Communication: Bacillus endolithicus and Bacillus paramycoides: New isolates from housefly Musca domestica in Saudi Arabia
}

\author{
DINA E. EL-GHWAS ${ }^{1, \boldsymbol{\vartheta}}$, ABIR S. AL-NASSER ${ }^{2}$, AISHA A. AL-SHEIKHY ${ }^{2}$ \\ ${ }^{1}$ Division of Pharmaceutical Industrial Research, Chemistry of Natural and Microbial products Department, National Research Centre, Dokki, Egypt, \\ •email: dinaelghwas7781@yahoo.com \\ ${ }^{2}$ Department of Biology, Faculty of Science, University of Jeddah. Hamzah Ibn Al Qasim St, Al Sharafeyah, Jeddah 23218, Saudi Arabia
}

Manuscript received: 23 May 2021. Revision accepted: 17 September 2021.

\begin{abstract}
El-ghwas DE, Al-Nasser AS, Al-Sheikhy AA. 2021. Short Communication: Bacillus endolithicus and Bacillus paramycoides: New Isolates from housefly Musca domestica in Saudi Arabia. Biodiversitas 22: 4209-4215. Housefly "Musca domestica" Linnaeus is a common insect widely distributed all over the world. It is one of the domestic insects found associated with humans and animals. The present study investigated the bacterial diversity associated with Musca domestica samples collected from different places such as food courts and trash cans near fast-food restaurants in Makkah Province from October 2019 to December 2019. Eighteen pure isolates of bacterial strains were isolated and identified by Gram staining. Most of the bacterial isolates were Gram-positive except for two species, which were Gram-negative. The VITEK system was used to identify randomly isolate no. 5, 7, 17, 18, and 29. The results revealed that they belonged to the genus Bacillus sp., Staphylococcus sp., Pseudomonas sp., and Micrococcus sp. respectively. Due to the most isolated strains were Bacillus sp., so 16S RNA was used to genetically identify novel isolated strains 5 and 7 . Isolate no. 5 showed the highest similarity (99\%) with Bacillus endolithicus, and isolate no. 7 showed the highest similarity (99\%) with Bacillus paramycoides. This is the first record of Bacillus endolithicus and Bacillus paramycoides to be isolated from the house fly Musca domestica L.
\end{abstract}

Keywords: Bacillus endolithicus, Bacillus paramycoides, Identification, Isolation, Musca domestica

\section{INTRODUCTION}

The common housefly Musca domestica Linnaeus can be found in human residences, hospitals, food processing factories, food markets, restaurants, poultry, livestock farms, and different domestic areas or buildings. It is a nuisance to humans, poultry, cattle, and other farm animals (Zahn and Gerry 2020). As a result of their lifestyle and behavior, flies are considered mechanical and biological vectors of pathogenic microbes (Kobayashi et al. 2020). One of the most dangerous features of the housefly is its popularity in food. Since they are attracted to the decaying plants and animal organisms, flies come in contact with ecosystems, litter, and animal waste (Park et al. 2019). Areas with a lot of manure or compost, such as kennels and areas without human sanitation, are major areas for the increase of houseflies and simultaneous detection of bacteria (Meerburg et al. 2007). However, the efficacy and distribution of species in animal droppings or manure vary greatly between sites and across host forces (Himathongkham et al. 1999). Therefore, flies may come in contact with and swallow highly variable amounts of bacteria during their contact with animal waste (Ahmad et al. 2011). Sulaiman et al. (2000) isolated various pathogenic organisms from the gut of flies $M$. domestica including Salmonella and Shigella species Flies are usually found in nasty places and later transmit these bacteria into food and water.
Furthermore, Park et al. (2019) investigated the internal and external microbiota of 400 samples of house flies from three different environments (cow farms, homes, and hospitals) in Belgium and Rwanda. They reported that whatever the country or habitat, house flies ported a high potential of various bacterial microbiota. They declared that the bacterial communities on the external body were much more diverse than the internal populations from the intestinal gut. Moreover, Rosef and Kapperud (1983) isolated 161 fragments of Campylobacter fetus subsp. jejuni from domestic flies. They found that $50.7 \%$ and $43.2 \%$ of their carriers were found in poultry and pig farms, respectively. Therefore, they concluded that flies play a key role in transmitting Campylobacter disease to humans by transmitting the virus from animals to humans. In addition, Rajendhran and Selvaraj (2003) identified fifteen species of pathogens in the mouth, and the external body of flies $M$. domestica collected from three different natural areas of Madurai, India. The five species most closely associated with flies were Streptococcus sp., Staphylococcus aureus, Shigella sp., Escherichia coli. and Salmonella sp.

Moreover, Khamesipour et al. (2018) isolated 130 pathogenic organisms from the houseflies in which bacteria were the most frequent. Also, Haeidari et al. (2021) studied the bacterial diversity isolated from the external surface of house flies collected from the hospitals in Yazd Province of Iran. They declared the presence of three species responsible for nosocomial infections such as Escherichia coli, Pseudomonas aeruginosa, and Staphylococcus aureus. 
The places from where the flies are collected are related to the microorganisms transmitted by these insects. Places such as hospitals and animal farms where antibiotic and growth stimulators are applied extensively showed flies carrying antimicrobial-resistant microorganisms (Nassiri et al. 2015; Nazari et al. 2017).

The kind and number of microorganisms that flies carry are closely related to the presence of the same organisms in the excreta and other wastes where flies develop and feed (Nichols 2005). An increasing problem in hospitals and other health care facilities is the involvement of houseflies in transmitting life-threatening antibiotic-resistant bacteria (Boulesteix et al. 2005; Macovei and Zurek 2006). Moreover, Heiden et al. 2020 investigated the bacterial fauna from 42 flies collected from a tertiary Rwandan hospital. They revealed that $48 \%$ (20/42) of the houseflies ported antibiotic-resistant bacteria and that all the strains were phenotypically multidrug-resistant (MRGN), including $E$. coli pathogenic lineage ST131, indicating the vital role of houseflies in spreading highly potent pathogens in medical locations and elsewhere. The present study aimed to investigate the bacterial diversity associated with housefly Musca domestica collected from and around restaurants and food court garbage to shed light on the importance of housefly control and maintaining a hygienic atmosphere to prevent the spread of diseases by this insect pest.

\section{MATERIALS AND METHODS}

\section{Collection of housefly samples}

Up to 20 adult houseflies, Musca domestica Linnaeus were randomly collected from October 2019 till December 2019 using an insect sweep net from various locations in Makkah Province, Saudi Arabia including food courts and trash cans near fast-food restaurants. Individual samples were placed in sterile test tubes and transported to the laboratory of the University of Jeddah for further analysis.

\section{Isolation and purification of bacterial strains}

All the media were prepared in an Erlenmeyer flask as directed by the manufacturer. Nutrient agar and Blood agar base medium were used as the media for the experiment. The media were autoclaved at $121^{\circ} \mathrm{C}$ for 15 minutes to sterilize them. Housefly samples were first destroyed by freezing them for 15 minutes at $4^{\circ} \mathrm{C}$. The isolation of bacterial strains from the body of houseflies was then done using two methods: the first was carried out according to Nwankwo et al. (2019) with some modifications, in which 10 samples of houseflies were washed twice with distilled water for 1 minute each time and then soaked in 0.85 percent saline so that the bacteria could be isolated. Under aseptic conditions, the yield solution was transferred to nutrient and blood agar plates, spread with a glass spreader, and incubated for 48 to 72 hours at $35-37^{\circ} \mathrm{C}$. The second approach was modified from that of Kassiri et al. (2012), in which 10 housefly samples were cleaned in $0.85 \%$ saline solution; then different body parts such as legs, antenna, wings, and head were cut and transferred to the surface of nutrient agar and blood agar plates under aseptic conditions and incubated for 48 to 72 hours at $35-37^{\circ} \mathrm{C}$. To ensure purity, the pure colonies were restreaked several times onto the surface of an agar plate on an isolation medium after the incubation period. Pure isolates were subcultured on nutrient agar medium slants and held at $4-5^{\circ} \mathrm{C}$ for further investigation (Atlas 1993).

\section{Identification of the most potent bacterial isolates}

The morphological characteristics of the cultured bacterial isolates were used to identify them, including colony morphology and Gram staining, as defined by (Baker 1967). The bacterial isolates were then classified using Bergey's Manual of Determinative Bacteriology 2005, 2009 and Automated Identification Systems (VITEK) based on their biochemical characteristics.

\section{Genetic identification of bacterial strains no. 5 and 7}

Individual colonies from randomly selected isolates 5 and 7 were inoculated in $3 \mathrm{~mL}$ of LB media and grown in a shaker bath at $37^{\circ} \mathrm{C}$ for 16 hours to confirm the identification of bacteria. DNeasy columns were used to remove DNA from each strain (QIAgen). The following primer collection was used to amplify the 16S RNA gene: SPIR F: 5' GAGTTTGATCCTGGCTCAG 3' and SPIR R: 5' AGAAAGGAGGTGATCAGCC 3' (Rainey et al. 1992). The amplification was carried out with $2 \mathrm{mM} \mathrm{MgCl} 2,200$ $\mathrm{mM}$ dNTPs, $0.4 \mathrm{M}$ of each primer, 1.25 units of Taq polymerase (Invitrogen), and a cycle programmed at $95^{\circ} \mathrm{C} / 3 \mathrm{~min}$, accompanied by 30 cycles of $95^{\circ} \mathrm{C} / 30 \mathrm{~s}$, $50^{\circ} \mathrm{C} / 1 \mathrm{~min}$, and $72^{\circ} \mathrm{C} / 2 \mathrm{~min}$, with a final extension of 10 minutes at $72^{\circ} \mathrm{C}$. The DNA band was cleaned from the agarose with a QIAquick Gel Extraction kit (QIAgen) and cloned into DH5- competent cells in a pGEM-T Simple vector (Promega) (Invitrogen). QIAprep Spin Miniprep kit was used to purify the plasmids (QIAgen). Big Dye Terminator Sequencing kit was used to sequence the inserted DNA using the vector primers T7 and SP6 (Applied Biosystems). Ethanol precipitation was used to extract the unincorporated labeled nucleotides, which were then sent to Sigma Company for processing. In our lab, the Sequencher software was used to analyze, edit, and align the resulting electropherograms (Gene Codes Corporation). BLASTn (http:// www.ncbi.nlm.nih.gov/BLAST/) was used to compare nucleotide sequences to a nucleotide database (Clark et al. 1974).

\section{RESULTS AND DISCUSSION}

After 24 to 72 hours of incubation at $35-37^{\circ} \mathrm{C}, 90 \%$ of the Petri dishes contained bacterial growth while $10 \%$ of the samples did not contain bacterial growth; therefore, those samples were excluded, as illustrated in Figure 1. Finally, 18 pure isolate strains were isolated. Nutrient agar medium, as well as blood agar medium, gave the same type of bacterial growth. Thus, the pure bacterial cultures were plated and maintained on the nutrient agar medium for further study. 


\section{Identification of isolated bacterial strains}

\section{Morphological characteristic}

The 18 bacterial isolates were identified to genus level by colony morphology, texture, and Gram staining according to Bergy's manual of systematic bacteriology 2005, 2009. As illustrated in Table 1, all the bacterial isolates were classified as Gram-positive except isolates no. 18 and 20, which were Gram-negative. The morphology of the colonies varied in color, size, and mucus formation. The cell shapes obtained were cocci, monococci, pairs, and rod in Gram-positive samples and rod shape in Gramnegative samples. Finally, the result demonstrated that the bacteria isolated from houseflies belong to four genera which are Bacillus sp. (14), Pseudomonas sp. (2), Micrococcus sp. (1), and Staphylococcus sp. (1). Most of the bacteria isolated were Gram-positive except for a few which were Gram-negative. Also, most isolates belonged to Bacillus sp.

\section{Automated identification systems (VITEK)}

To confirm the genus level of bacterial isolates under study, Automated Identification Systems (VITEK) was used Bacillus sp. Isolate no. 5, 7, 17, 18, and 29 were chosen randomly for the confirmation process. The results indicated that isolate no. 5 and 7 were Gram-positive, rodshaped, and the colony was spherical. On the other hand, isolate no. 17 and 29 were Gram-positive and cocci, while isolate No. 18 was Gram-negative and rod-shaped. Also, the results proved that isolate no. 5 and 7 belonged to the genus Bacillus sp., isolate no. 17 belonged to Staphylococcus sp., isolate no. 29 belonged to Micrococcus sp. and isolate no. 18 was Pseudomonas sp.

\section{Genetic identification of most potent bacterial strain}

Molecular analysis of $16 \mathrm{~S}$ RNA was used as the confirmation test with the most potent bacterial isolates 5 and 7 , which were widely distributed. The $16 \mathrm{~S}$ rRNA was amplified by PCR using universal forward and reverse primers. The DNA of the two isolates 5 and 7, was then isolated and purified from the agarose gel and sequenced on an automated sequencer. The sequence data of the isolates were then analyzed by comparison with its GenBank database. The obtained results revealed that the sequence of isolate no. 5 showed the highest similarity (99 $\%$ ) with Bacillus endolithicus as illustrated in Figure 2. On the other hand, the sequence of isolate no. 7 showed the highest similarity (99\%) with Bacillus paramycoides, as illustrated in Figure 3.

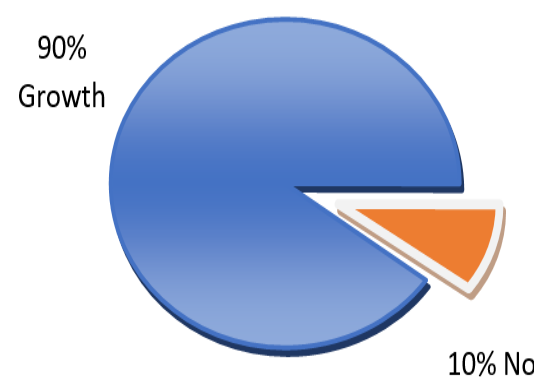

Figure 1. Infection percentage in 20 samples of Musca domestica Table 1. Morphological characteristic and Gram stain of bacterial isolates

\begin{tabular}{ccc}
\hline Sample no. & Gram stain & Colony color and cell shape \\
\hline & + & White/ cocci \\
2 & + & White/ rod \\
3 & + & White/rod \\
4 & + & White/rod \\
5 & + & yellow/rod \\
7 & + & White mucus/rod \\
10 & + & White/rod \\
11 & + & White/rod \\
12 & + & White/rod \\
17 & + & Smooth, glossy, opaque \\
& & yellow/Staphylococcus \\
18 & - & White hairy/rod \\
20 & - & Yellow/rod \\
21 & + & White/rod \\
28 & + & White Creamy/rod \\
29 & + & Yellow, smooth/cocci \\
$40-(10)$ & + & White/rod \\
$40-(11)$ & + & White/rod \\
$41-(12)$ & + & White/cocci \\
& &
\end{tabular}

\section{Discussion}

Houseflies transmit microorganisms in homes, hospitals, and farms. They spread these microorganisms when they sit on pollutants for ovipositing their eggs, where various parts of their body (legs, parts of the mouth, and wings) get contaminated with various pathogenic microorganisms (Bahrndorff et al. 2017; Manandhar and Gokhale 2017). These reports agree with the findings of the present study, in which different strains of the virus were isolated from the outside and various body parts of sample houseflies that were collected $(n=20)$. The presence of these bacterial species may be related to the various places from where the samples of houseflies (food courts, cans of garbage in fast-food restaurants in the province of Makkah) were collected, which could be loaded with strong bacteria.

The separation process was composed of two solutions based on the surface of the outer body of the housefly M. Domestica and parts of the mouth, legs, and wings. After the discovery of bacterial classification by morphological and gram stain technique, the results showed that the isolated bacteria belonged to the 4th generation: Bacillus sp. (14), Pseudomonas sp. (2), Micrococcus sp. (1), and Staphylococcus sp. (1). Most isolated bacteria were Grampositive except for a few which were Gram-negative. Moreover, most of the separated ones belonged to Bacillus sp.

On the other hand, the identification to genus level was done by the biochemical tested automated identification systems (VITEK). Isolate no. 5, 7, 18, 17, and 29 were randomly selected for the confirmation process. The results proved that isolates 5, 7, 17, 18, and 29 were Bacillus sp., Staphylococcus sp., Pseudomonas sp., and Micrococcus sp., respectively. 


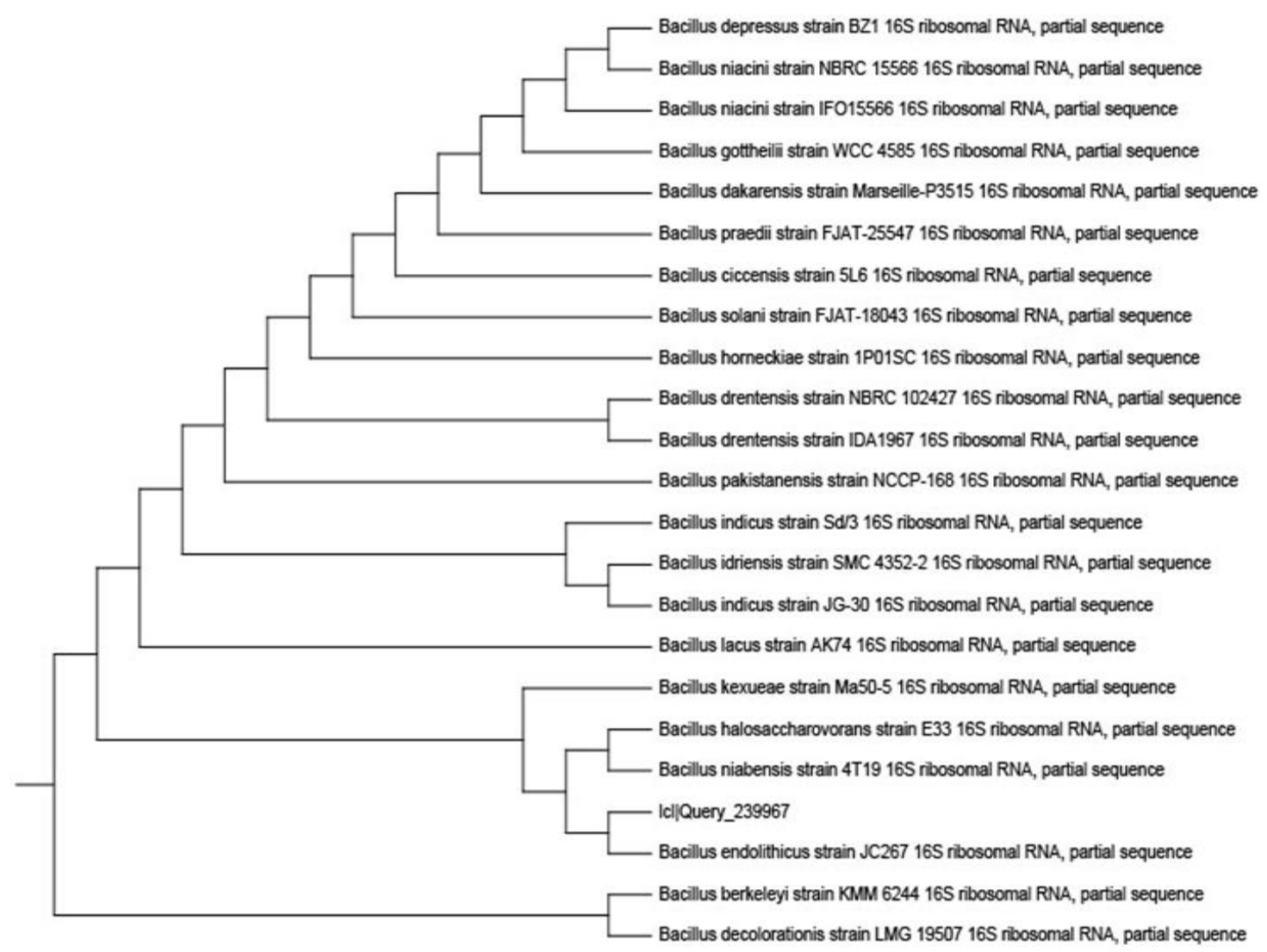

Figure 2. The phylogenetic tree of isolate no. 5 (Bacillus endolithicus) and other Bacillus sp. constructed using the neighbor-joining method

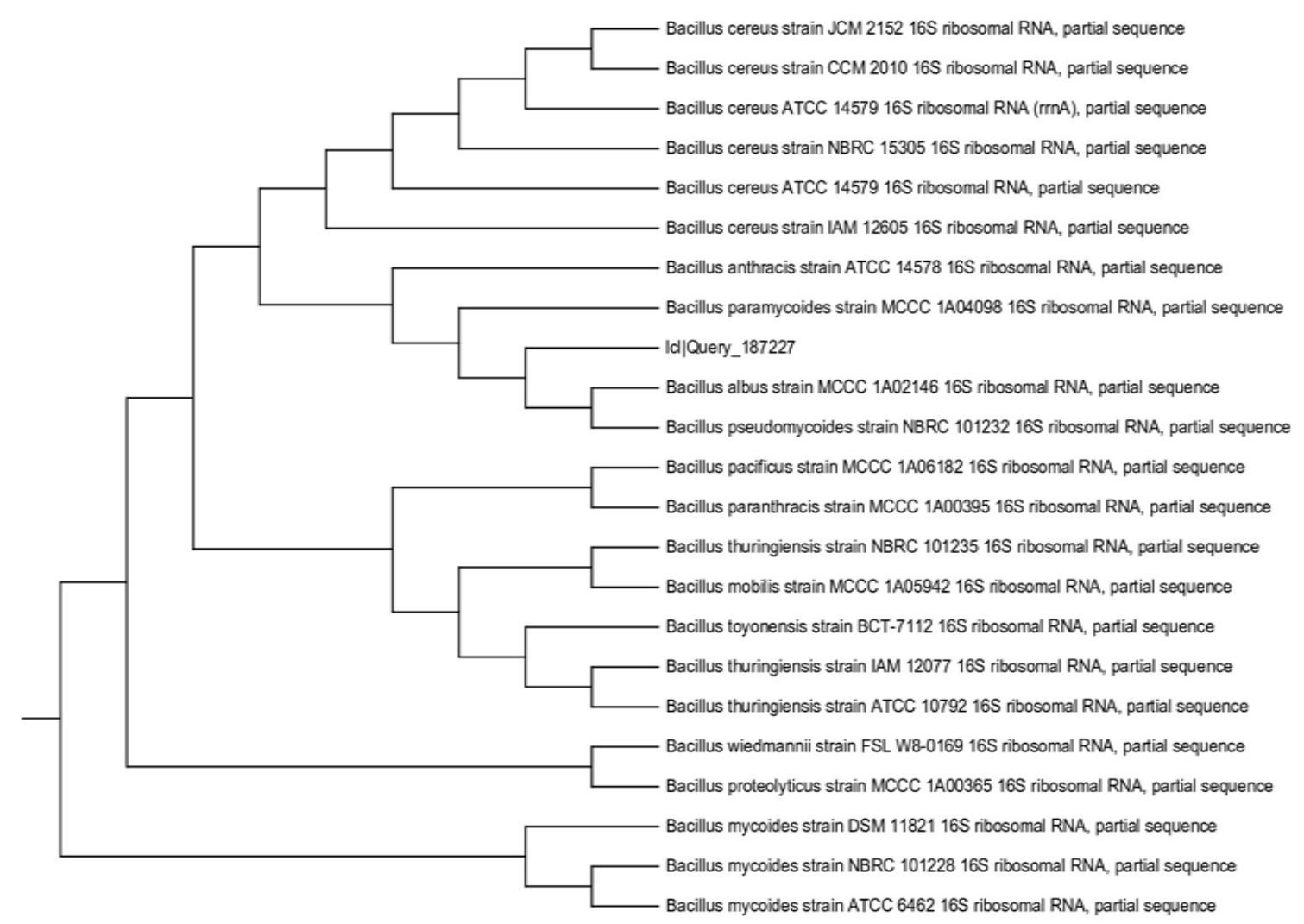

Figure 3. The phylogenetic tree of isolate no. 7 (Bacillus paramycoides) and other Bacillus sp. constructed using the neighbor-joining method 
In addition, the molecular analysis of 16S RNA was used as the confirmation test for the highly potent bacterial isolates 5 and 7, which were widely distributed. The results obtained showed that isolate no. 5 showed the highest similarity (99\%) with Bacillus endolithicus, while isolate no. 7 showed the highest similarity $(99 \%)$ with Bacillus paramycoides. This is the first record of Bacillus endolithicus and Bacillus paramycoides obtained from the housefly Musca domestica L. The same methods of classification were used in previous studies (Songe et al. 2017; Ibrahim 2018; Khamesipour et al. 2018; Neupane et al. 2019; Akter et al. 2020).

Khamesipour et al. (2018) reported that the bacteria were significantly isolated from flies as they adhere to different parts of the body (mouth, wings, and legs). Förster et al. (2007) found Bacillus spp. on the surface of the body of houseflies. In addition, Nazni et al. (2005) recorded Bacillus sp., Acinetobacter sp., Proteus sp., and Enterobacter sp. from the surface of the body of $M$. domestica. On the other hand, Songe et al. (2017) discovered the most common infectious species of Escherichia coli from domestic houseflies, Vibrio cholera and Bacillus anthracis. Also, Ibrahim (2018) observed that 23 species of bacteria isolated from the surface of the body and intestines of houseflies were Gram-negative bacteria (Escherichia coli, Salmonella sp., Pseudomonas sp. Shigella sp., and Klebsiella sp.), while seven species were Gram-positive bacteria. (Staphylococcus sp., Streptococcus sp., Bacillus sp.). Also, it was reported that the majority of species isolated from houseflies collected from hospital areas were $78.6 \%$ Staphylococcus aureus, $66.4 \%$ Salmonella spp., and 51.4\% Escherichia coli. Heiden et al. (2020) recorded many drug-resistant bacteria in houseflies, including $E$. coli pathogenic offspring ST131.

Current research has confirmed the ability of houseflies to control and transmit a wide variety of germs, such as Pseudomonas, Bacillus, Micrococcus, and Staphylococcus. Therefore, studies should be carried out on how to prevent houseflies from spreading infectious diseases.

\section{ACKNOWLEDGEMENTS}

The authors would like to thank the Faculty of Sciences, University of Jeddah, Jeddah, Saudi Arabia, and the National Research Centre, Dokki, Giza, Egypt.

\section{REFERENCES}

Ahmad A, Ghosh A, Schal C, Zurek L. 2011 Insects in confined swine operations carry a large antibiotic resistant and potentially virulent enterococcal community. BMC Microbiol 11 (1): 1-13. DOI: 10.1186/1471-2180-11-23.

Akter S, Sabuj AAM, Haque ZF, Rahman MT, Kafi MA, Saha S. 2020. Detection of antibiotic-resistant bacteria and their resistance genes from houseflies. Vet World 13 (2): 266-274. DOI: 10.14202/vetworld.2020.266-274

Atlas RM 1993. Handbook of microbiological media. CRC press.

Bahrndorff S, de Jonge N, Skovgård H, Nielsen JL 2017. Bacterial Communities Associated with Houseflies (Musca domestica L.) sampled within and between farms. PloS One 12 (1): e0169753. DOI: 10.1371/journal.pone.0169753
Baker FJ. 1967. Handbook of bacteriological technique, 2nd ed. Butterworth and Co. Ltd., London.

Boulesteix G, Le Dantec P, Chevalier B, Dieng M, Niang B, Diatta B. 2005. Role of Musca domestica in the transmission of multiresistant bacteria in the centers of intensive care setting in a sub-Saharan Africa. Annales Françaises d'Anesthésie et de Réanimation 24 : 361365. DOI: 10.1016/j.annfar.2005.01.016

Clark PU, Botella LM, Moya A. 1974. Larval stop, delayed development and survival in overcrowded cultures of Drosophila melanogaster, effect of urea and uric acid. J Insect Physiol 31: 179-185. DOI: 10.1016/0022-1910(85)90118-0

Davari B, Kalantar E, Zahirnia A, Moosa-Kazemi SH. 2010. Frequency of resistance and susceptible bacteria isolated from houseflies. Iran $\mathbf{J}$ Arthropod-Borne Dis 4 (2): 50-55.

Förster M, Klimpel S, Mehlhorn H, Sievert K, Messler S, Pfeffer K. 2007. Pilot study on synanthropic flies (e.g. Musca, Sarcophaga, Calliphora, Fannia, Lucilia, Stomoxys) as vectors of pathogenic microorganisms. Parasitol Res 101: 243-246. DOI: 10.1007/s00436007-0522-y

Haeidari A, Keshavarzi D, Owlia P, Vatandoost H, Rafinejad A, Rafinejad J. 2021. Isolation and enumeration of bacteria responsible for nosocomial infections from houseflies and determining their susceptibility to poison bait. Nusantara Biosci 13 (1): 24-28. DOI: 10.13057/nusbiosci/n130104

Heiden SE, Kurz M, Bohnert J, Bayingana C, Ndoli JM, Sendegeya A, Gahutu JB, Eger E, Mockenhaupt FP, Schaufler K. 2020. Flies from a tertiary hospital in Rwanda carry multidrug-resistant Gram-negative pathogens including extended-spectrum beta-lactamase-producing $E$. coli sequence type 131. Antimicrob Resist Infect Control 9 (1): 34. DOI: $10.1186 / \mathrm{s} 13756-020-0696-y$

Hemmatinezhad B, Ommi D, Hafshejani TT, Khamesipour F. 2015. Molecular detection and antimicrobial resistance of Pseudomonas aeruginosa from houseflies (Musca domestica) in Iran. J Venom Anim Toxins including Trop Dis 21: 1-5. DOI: 10.1186/s40409-0150021-z

Himathongkham S, Bahari S, Riemann H, Cliver D. 1999. Survival of Escherichia coli O157:H7 and Salmonella typhimurium in cow manure and cow manure slurry. FEMS Microbiol Lett 178: 251-257. DOI: 10.1111/j.1574-6968.1999.tb08684. x

Ibrahim AW, Ajiboye TO, Akande TA, Anibaba OO. 2018. Isolation and identification of pathogenic microorganisms from houseflies. Glob J Sci Front Res: C Biol Sci 18 (1): 57-64.

Kassiri H, Akbarzadeh K, Ghaderi A. 2012. Isolation of pathogenic bacteria on the house fly, Musca domestica L. (Diptera: Muscidae), body surface in Ahwaz Hospitals, Southwestern Iran. Asian Pac J Trop Biomed 2 (2): 1116-1119. DOI: 10.1016/S2221-1691(12)603700

Khamesipour F, Lankarani KB, Honarvar B, Kwenti TE. 2018. A systematic review of human pathogens carried by the housefly (Musca domestica L.). BMC Public Health 18: 1049. DOI: 10.1186/s12889-018-5934-3

Kobayashi M, Ooi HK, Taira K. 2020. Effects of anthelmintics on the pinworm Blatticola blattae in laboratory-reared German cockroaches Blattella germanica. Parasitol Res 119 (9): 3093-3097. DOI: 10.1007/s00436-020-06778-1

Macovei L, Zurek L. 2006. Ecology of antibiotic resistance genes: Characterization of enterococci from houseflies collected in food settings. Appl Environ Microbiol 72: 4028-4035. DOI: 10.1128/AEM.00034-06

Manandhar R, Gokhale S. 2017. Are houseflies still important vector of gastrointestinal infections? J Bacteriol Parasitol 8 (4): 318. DOI: 10.4172/2155-9597.1000318

Meerburg BG, Vermeer HM, Kijlstra A. 2007. Controlling risks of pathogen transmission by flies on organic pig farms: a review. Outlook Agric 36: 193-197. DOI: 10.5367/000000007781891432

Nassiri H, Zarrin M, Veys-Behbahani R, Faramarzi S, Nasiri A. 2015. Isolation and identification of pathogenic filamentous fungi and yeasts from adult house fly (Diptera: Muscidae) captured from the hospital environments in Alivaz city, Southwestern Iran. J Med Entomol 52 (6): 1351-1356. DOI: 10.1093/jme/tjv140

Nazari M, Mehrabi T, Hosseini SM, Alikhani MY 2017. Bacterial contamination of adult house flies (Musca domestica) and sensitivity of these bacteria to various antibiotics, captured from Hamadan City, Iran. J Clin Diagn Res 11 (4): DC04-DC07. DOI: 10.7860/JCDR/2017/23939.9720 
Nazni WA, Seleena B, Lee HL, Jeffery JT, Rogayah TAR, Sofian MA 2005. Bacteria fauna from the house fly, Musca domestica (L.). Trop Biomed 22 (2): 225-231.

Neupane S, Nayduch D, Zurek L. 2019. House flies (Musca domestica) pose a risk of carriage and transmission of bacterial pathogens associated with Bovine Respiratory Disease (BRD). Insects 10: 358 DOI: $10.3390 /$ insects 10100358

Nichols GL. 2005. Fly transmission of campylobacter. Emerg Infect Dis 11 (3): 361-364. DOI: 10.3201/eid1103.040460

Nwankwo EO, Ekemezie CL, Adeyemo S. 2019. Evaluation of microbial flora of the external surface of housefly (Musca domestica) in Umuahia Metropolis, Abia State, Southeast Nigeria. Calabar J Health Sci 3 (1): 9-15. DOI: 10.25259/CJHS_5_2019

Park R, Dzialo MC, Spaepen S, Nsabimana D, Gielens K, Devriese H, Crauwels S, Tito RY, Raes J, Lievens B. Verstrepen KJ 2019. Microbial communities of the house fly Musca domestica vary with geographical location and habitat. Microbiome 7: 147. DOI: 10.1186/s40168-019-0748-9

Rainey FA, Dorsch M, Morgan HW, Stackebrandt E. 1992. 16S rDNA analysis of Spirochaeta thermophila: Its phylogenetic position and implications for the systematics of the order Spirochaetales. Syst Appl Microbiol 15 (2): 197-202. DOI: 10.1016/S0723-2020(11)80092-5

Rajendhran J, Pandian RS. 2003. Microbial flora isolated from an urban population of non-biting vector, Musca domestica and their susceptibility to antibiotics. Asian J Microbiol Biotechnol Environ Sci 5: 381-385

Rosef O, Kapperud G. 1983. House flies (Musca domestica) as possible vectors of Campylobacter fetus subsp. jejuni. Appl Environ Microbiol 45 (2): 381-383. DOI: 10.1128/AEM.45.2.381-383.1983

Solà-Ginés M, González-López JJ, Cameron-Veas K, Piedra-Carrasco N, Cerdà-Cuéllar M, Migura-Garcia L. 2015. Houseflies (Musca domestica) as vectors for extended-spectrum $\beta$-Lactamase-Producing Escherichia coli on spanish broiler farms. Appl Environ Microbiol 81 (11): 3604-3611. DOI: 10.1128/AEM.04252-14

Songe MM, Hang'ombe BM, Knight-Jones TJ, Grace D. 2017. Antimicrobial resistant enteropathogenic Escherichia coli and Salmonella spp. in houseflies infesting fish in food markets in Zambia. Int J Environ Res Public Health 14 (1): 21. DOI: 10.3390/ijerph14010021

Sulaiman S, Othman MZ, Aziz AH 2000. Isolations of enteric pathogens from synanthropic flies trapped in downtown Kuala Lumpur. J Vector Ecol 25: 90-93.

Zahn LK, Gerry AC. 2020. Diurnal flight activity of house flies (Musca domestica) is influenced by sex, time of day, and environmental conditions. Insects 11 (6): 391-396. DOI: 10.3390/insects11060391

Zurek L, Ghosh A. 2014. Insects represent a link between food animal farms and the urban environment for antibiotic resistance traits. Appl Environ Microbiol 80: 3562-3567. DOI: 10.1128/AEM.00600-14 